\title{
Seasonal fluctuation of organic and inorganic components in xylem sap of Populus nigra
}

\author{
Jun Furukawa ${ }^{1 \dagger}$, Yuta Abe ${ }^{1 \dagger}$, Hiroaki Mizuno ${ }^{1}$, Kaoru Matsuki ${ }^{1}$, Keiko Sagawa ${ }^{1}$, Mikiko \\ Kojima ${ }^{2}$, Hitoshi Sakakibara ${ }^{2}$, Hiroaki Iwai ${ }^{1}$ and Shinobu Satoh ${ }^{1}$ \\ ${ }^{1}$ Graduate School of Life and Environmental Sciences, University of Tsukuba, Tennodai 1-1-1, Tsukuba 305-8572, \\ Japan \\ ${ }^{2}$ RIKEN Plant Science Center, Suehiro-cho 1-7-22, Tsurumi, Yokohama 230-0045, Japan \\ ${ }^{\dagger}$ These two authors contributed equally to this work \\ Corresponding author: S. Satoh, E. mail: satoh.shinobu.ga@u.tsukuba.ac.jp, Phone: +81-29-853-4672, Fax: \\ $+81-29-853-4579$
}

Received on September 7, 2011; Accepted on October 31, 2011

\begin{abstract}
Deciduous trees show annual periodicity in shoot growth and development, but such periodicity is not well investigated in roots. To clarify the seasonal fluctuation in root functions, xylem sap from Populus nigra branches was analyzed for 2 years. Various xylem sap components including calcium, potassium, glucose, and proteins showed seasonal fluctuations with peaks from winter to spring. Abscisic acid (ABA) was the most abundant hormone in the xylem sap throughout all seasons and showed two peaks from late autumn to spring. We hypothesize that low temperature in winter promotes metal loading into the xylem sap and the synthesis of proteins and sugars in roots as an adaptation to the winter environment and to prepare for spring bud burst.
\end{abstract}

Keywords: calcium, glucose, poplar (Populus nigra), protein, winter, xylem sap

\begin{abstract}
Abbreviations: $t Z$, trans-zeatin; $t Z R, t Z$ riboside; tZRPs, tZR 5'-phosphates; cZ, cis-zeatin; cZR, cZ riboside; cZRPs, cZR 5'-phosphates; DZ, dihydrozeatin; DZR, DZ riboside; DZRPs, DZR 5'-phosphates; iP, $N^{6}$-( $\Delta^{2}$-isopentenyl)adenine; iPR, iP riboside; iPRPs, iPR 5'-phosphates; tZ7G, tZ-7- $N$-glucoside; tZ9G, tZ-9- $N$-glucoside; tZOG, tZ-O-glucoside; cZOG, cZ-O-glucoside; tZROG, tZR-O-glucoside; $\quad$ cZROG, $\quad$ cZR-O-glucoside; tZRPsOG, tZRPs- $O$-glucoside; cZRPsOG, cZRPs- $O$ glucoside; DZ9G, DZ-9- $N$-glucoside; iP7G, iP-7- $N$ glucoside; iP9G, iP-9- $N$-glucoside; IAA, indole-3-
\end{abstract}

acetic acid; IA-Ala, indole-3-acetyl- L-alanine; IA-Ile, indole-3-acetyl-L-isoleucine; IA-Leu, indole-3-acetylL-leucine; IA-Asp, indole-3-acetyl-L-aspartic acid; IA-Trp, indole-3-acetyl-L-tryptophan; IA-Phe, indole3-acetyl-L-phenylalanine; GA gibberellic acid; ABA, abscisic acid

\section{Introduction}

The seasonal cycle of growth and dormancy is a distinct characteristic of perennial plants, with this phase change representing one of the most basic adaptations of trees to their environment. Seasonal changes in the amount of substances in the xylem sap of woody plants (Tromp and Ovaa 1990, Bertrand et al. 1997) suggest that root functions are regulated by environmental factors in the root and/or by shoot-synthesized signals. In spite of the importance of bidirectional signal transfer between shoots and roots for the environmental adaptation of plants, studies related to the annual rhythms of woody plants have focused on shoots. In deciduous trees, root growth and the uptake of water and mineral nutrients are initiated in advance of dormancy break and shoot growth (Teskey and Hinckley 1981, Lachaud 1989). Moreover, root starch stored in the winter season is degraded to disaccharides or monosaccharides that are transported to the shoot and contribute to shoot growth after dormancy break (Canam et al. 2008). Hence, the annual growth rhythms in woody plants are different in shoots and roots. Although annual rhythms of root function are difficult to physiologically study in trees because of the lack of model woody plants used for 
molecular research, elucidation of the entire Populus trichocarpa genome (Tuskan et al. 2006) and identification of expressed sequence tags of Populus (Kohler et al. 2003, Sterky et al. 2004) have triggered molecular biological research in deciduous trees. The increasing information about dormancy makes poplar one of the best model deciduous trees for investigating growth rhythms. In this study, seasonal changes in the composition of organic and inorganic substances of poplar xylem sap were analyzed to elucidate the annual rhythms of root function and the involvement of xylem sap substances in winter adaptation.

\section{Materials and Methods}

\section{Plant material and climate}

Xylem sap was collected from a Populus nigra plant $(80 \mathrm{~cm}$ in diameter) growing at the University of Tsukuba in Ibaraki, Japan (latitude $36^{\circ} 05^{\prime} \mathrm{N}, 140^{\circ}$ $07^{\prime} \mathrm{E}$; altitude $25 \mathrm{~m}$ ). We used one tree for the collection of xylem sap, near the university building where the electricity is available for the collection equipment. During the experimental period (from February 8, 2007 to October 8, 2008), local air temperatures of the two winter seasons were obtained from the Agricultural and Forestry Research Center of University of Tsukuba (Fig. 1). The second season had a decrease in temperature, especially the minimum temperature, that occurred about 1 month earlier than in the first season, as well as a longer period of average temperatures below $5.0^{\circ} \mathrm{C}$. Temperatures in March and April were similar in both seasons.

\section{Collection of xylem sap}

To collect poplar xylem sap, a side branch $(2.0 \mathrm{~cm}$ in diameter) was cut $\sim 1.0 \mathrm{~m}$ above the soil surface. The cut branch surface was rinsed with distilled water and connected via a tube to a sample collection container (Fig. 2). The container was maintained at $-0.08 \mathrm{MPa}$ with a vacuum pump for $12 \mathrm{~h}$. The sampling time was fixed from 8 a.m. to 8 p.m. to exclude the effect of diurnal fluctuation of xylem sap components, as shown by Mayrhofer et al. 2004. During the collection period, the temperature of the container and xylem sap was kept below $10^{\circ} \mathrm{C}$. The xylem sap was then stored at $-30^{\circ} \mathrm{C}$ until further analysis. Samples were collected in 2007 (February 8; March 3, 15, and 25; July 6; November 6; and December 3) and in 2008 (January 11, February 4 and 18, June 14, and October 8).

\section{Measurement of xylem sap substances}

To measure inorganic elements, xylem sap was

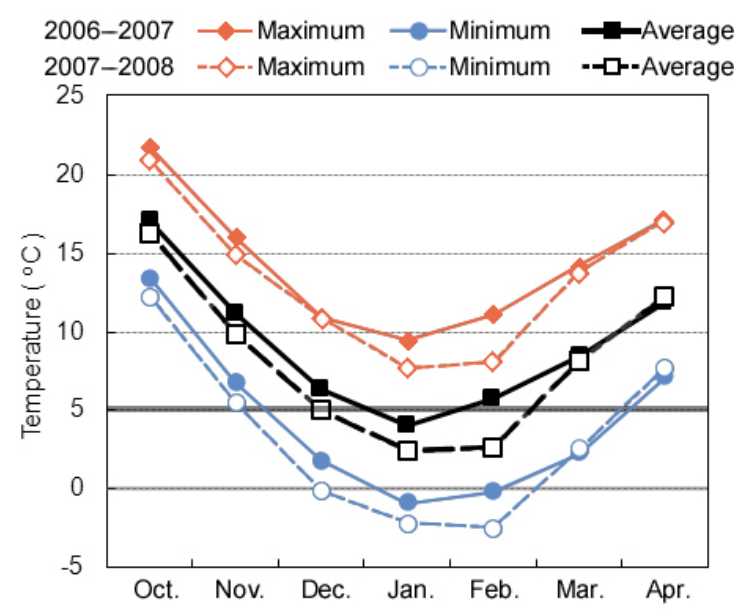

Fig. 1. Monthly maximum, minimum, and average air temperatures at the experimental site during the winters of 2006 to 2007 and 2007 to 2008.
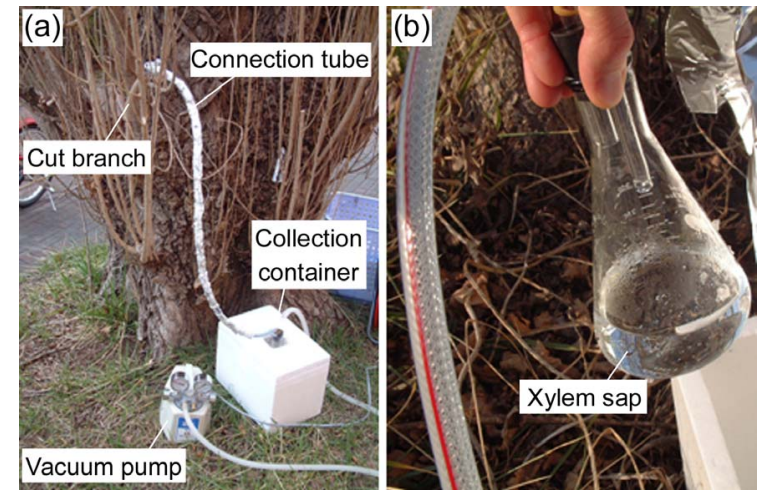

Fig. 2. Xylem sap collection with $P$. nigra. The cut branch was connected via a tube to a sample collection container and the container was maintained at $-0.08 \mathrm{MPa}$ with a vacuum pump (a). During the collection period, xylem sap was stored in the flask and the temperature of the container and xylem sap was kept below $10^{\circ} \mathrm{C}(\mathrm{b})$.

filtered through a $0.22-\mu \mathrm{m}$ membrane (Millipore, Billerica, MA, USA) and analyzed for $\mathrm{Na}, \mathrm{Mg}, \mathrm{K}, \mathrm{Ca}$, $\mathrm{Mn}, \mathrm{Fe}, \mathrm{Co}, \mathrm{Ni}$, and $\mathrm{Zn}$ by inductively coupled-plasma atomic emission spectrometry (ICP-757, Jarrell-Ash, Franklin, MA, USA) at Chemical Analysis Center, University of Tsukuba. Ionic components $\left(\mathrm{F}^{-}, \mathrm{PO}_{4}{ }^{3-}, \mathrm{SO}_{4}{ }^{2-}\right.$, and $\left.\mathrm{Cl}^{-}\right)$in filtered xylem sap were analyzed by ion chromatography (IC-1000, Yokogawa Electric Corporation, Tokyo, Japan). The $\mathrm{NH}_{4}{ }^{+}$concentration was measured using the indophenol method according to Sagi (1966). Concentrations of all other ionic components and inorganic elements were calculated using standard solutions (Wako Pure Chemical Industries, Osaka, Japan). For sugar purification, the sugars in $1 \mathrm{ml}$ of 
sap were absorbed by Sep-Pak $\mathrm{NH}_{2}$ columns (Waters, Milford, MA, USA), washed with $1 \mathrm{ml}$ of distilled water, eluted with $2 \mathrm{ml}$ of $80 \%(\mathrm{v} / \mathrm{v})$ acetonitrile, and then dried by evaporation. Glucose and sucrose were measured using glucose and sucrose assay kits (Bio Vision, Mountain View, CA, USA). To analyze amino acids, a mixture of $2 \mathrm{ml}$ xylem sap and $8 \mathrm{ml} \mathrm{100 \%}$ ethanol was centrifuged at $18000 \times \mathrm{g}$ for $30 \mathrm{~min}$ at $4^{\circ} \mathrm{C}$ and the supernatant was collected and freeze dried. Samples were re-dissolved in $0.5 \mathrm{ml}$ of $0.2 \mathrm{M}$ sodium phosphate buffer ( $\mathrm{pH} 6.5$ ), filtered through a $0.22-\mu \mathrm{m}$ membrane (Millipore), and adjusted to $\mathrm{pH} 2-3$. Amino acid concentrations were determined using an amino acid analyzer (JLC-500/V2, JEOL, Tokyo, Japan). Citrate and malate concentrations were quantified using the enzymatic method of Delhaize et al. (1993), using 0.3 and $0.2 \mathrm{ml}$ of xylem sap, respectively. Plant hormones were measured with the mass spectrometry (MS)-probe method using $2 \mathrm{ml}$ of xylem sap according to Kojima et al. (2009). The total protein in $10 \mathrm{ml}$ of xylem sap was precipitated with $80 \%(\mathrm{v} / \mathrm{v})$ ethanol at $4^{\circ} \mathrm{C}$ overnight, collected by centrifugation at $18000 \times \mathrm{g}$ for $30 \mathrm{~min}$ at $4^{\circ} \mathrm{C}$, and re-dissolved in $200 \mu \mathrm{l}$ of distilled water, and the protein concentration was determined using a protein assay kit (Bio-Rad, Hercules, CA, USA) with bovine serum albumin as a standard.

\section{Results and Discussion}

Comprehensive analysis of the organic and inorganic substances in xylem sap was performed using the poplar xylem sap collected in two years (Table 1). Since the concentration figures of xylem sap substances showed small fluctuations, we focused mainly on the obvious changes indicating seasonal pattern.

The amount of xylem sap obtained at $-0.08 \mathrm{MPa}$ differed between collection seasons (Fig. 3a). The xylem sap amount tended to increase during the winters, with the maximum amount obtained in March 2007 and February 2008. The amount of xylem sap obtained under a constant vacuum pressure is thought to reflect root hydraulic conductivity (Freundl et al. 1998, Hose et al. 2000). Increased conductivity in early spring may reflect water supply to the leafless shoot with weak transpiration. Considering the status of trees, such as age and growing conditions, estimation of flow volume based on the literature was difficult. However, the real flow volume is supposed to be larger than artificially obtained volume under constant negative pressure in leaf-expanded summer season with active transpiration and smaller in leafless winter season. Therefore, the concentrations of each component really translocated in xylem sap might be lower and higher than our results in summer and winter seasons, respectively. The possible difference between real flow volume and artificially obtained volume suggests that the concentrations of each component in the sap in intact xylem vessels might more drastically fluctuate comparing to our results.

Throughout the experimental period, potassium $(\mathrm{K})$ and calcium $(\mathrm{Ca})$ were abundant in the xylem sap, with peak concentrations in March during the first winter and in December $(\mathrm{K})$ and January $(\mathrm{Ca})$ during the second winter (Fig. 3a). Magnesium (Mg) exhibited a low, broad peak in March and December in 2007 and 2008, respectively (Fig. 3a). Freezing-induced $\mathrm{Ca}^{2+}$ influx from extracellular spaces has been reported to trigger the resealing of puncture sites by membrane fusion (Yamazaki et al. 2008). In our experiments, $\mathrm{Ca}$ in xylem sap peaked at $2-3 \mathrm{mM}$, which may contribute to exocytosis-mediated freezing tolerance mechanisms in poplar shoot cells during winter. The concentrations of inorganic elements, especially $\mathrm{K}$ and $\mathrm{Ca}$, were much higher in winter to early spring, but such tendency was observed neither in inorganic or organic anions including acidic amino acids and organic acids (Table 1). Since those inorganic elements are known to be translocated in the form of cationic ion, sum of cationic ions might be much higher than that of anionic ions in the winter xylem sap, though not all of anionic components in the xylem sap were measured. It might be possible that the balance between cations and anions in xylem sap is disrupted in winter.

Escher et al. (2004) reported that glucose and sucrose concentrations gradually decrease from spring to autumn in Populus $\times$ euramericana. In our study, however, the glucose concentration clearly increased in March 2007 and January 2008 and sucrose levels were low throughout the experimental period (Fig. 3c). Though the local exchange of sugars may occur between the vessels and parenchyma cells in stem (Sauter et al. 1973), the source of xylem sap glucose was not well identified. The accumulation of free sugars in the xylem sap may promote water movement into xylem vessels to refill embolized xylem by decreasing osmotic potential (Améglio et al. 2001, Sakr et al. 2003).

ABA was the most abundant plant hormone in xylem sap in all seasons, peaking at $\sim 20 \mathrm{nM}$ (Fig. 3b). In the second year, ABA concentration increased in late autumn and early spring with a temporal decrease during the cold period. Xylem sap ABA peaks around December in sugar maple, although the species are different, suggesting that winter acclimation triggers the ABA increase to a peak level just before maximum acclimation (Bertrand et al. 1997). Winter acclimation of poplar initiated under the regulation of ABA (Ruttink et al. 2007), and after the late stage of acclimation, most of Populus species can survive well against the temperatures below $-60^{\circ} \mathrm{C}$ (Renaut et al. 
2005). Therefore, the ABA increase before the cold period in our study may also have been related to cold acclimation. Aquaporins play a key role in radial water transport in roots under both hydrostatic and osmotic gradients (Martre et al. 2002, Javot et al. 2003, Maurel 2007), and their gene expression is induced by

Table 1 Substances identified in xylem sap obtained at each sampling date from Populus nigra growing at the University of Tsukuba. Bar (-) means "under quantification limit". $\mathrm{GA}_{1}$ to $\mathrm{GA}_{53}$ are bioactive gibberellic acids and intermediates in its biosynthetic pathway. Among 43 investigated plant hormones, tZOG, DZ9G, iP7G, IA-Ala, IA-Leu, IA-Asp, IA-Trp, IA-Phe, $\mathrm{GA}_{1}, \mathrm{GA}_{3}, \mathrm{GA}_{4}, \mathrm{GA}_{7}, \mathrm{GA}_{8}, \mathrm{GA}_{9}, \mathrm{GA}_{12}$ and $\mathrm{GA}_{24}$ were under quantification limit at all sampling date

\begin{tabular}{|c|c|c|c|c|c|c|c|c|c|c|c|c|}
\hline \multirow{2}{*}{ Xylem sap substances } & \multicolumn{7}{|c|}{2007} & \multicolumn{5}{|c|}{2008} \\
\hline & Feb. 8 & Mar. 3 & Mar. 15 & Mar. 25 & Jul. 16 & Nov. 6 & Dec. 3 & Jan. 11 & Feb. 4 & Feb. 18 & Jun. 14 & Oct. 8 \\
\hline Amount of xylem sap $(\mathrm{ml}) / 12 \mathrm{~h}$ & 216.0 & 247.2 & 396.0 & 288.0 & 166.6 & 96.0 & 155.3 & 120.0 & 228.0 & 192.0 & 171.6 & 225.0 \\
\hline \multicolumn{13}{|l|}{ Inorganic elements $(\mu \mathrm{M})$} \\
\hline $\mathrm{Na}$ & - & - & - & - & - & - & 23.9 & - & - & - & - & - \\
\hline $\mathrm{Mg}$ & 32.1 & 241.6 & 208.8 & 474.7 & 63.9 & 31.1 & 314.4 & 312.0 & 200.8 & 50.3 & 97.0 & \\
\hline $\mathrm{K}$ & 670.0 & 898.7 & 978.5 & 1882.3 & 561.0 & 842.8 & 2648.0 & 1491.1 & 872.2 & 444.2 & 1101.3 & 212.7 \\
\hline $\mathrm{Ca}$ & 590.8 & 1840.3 & 1289.1 & 3087.5 & 432.2 & 504.6 & 2380.3 & 2885.5 & 2122.7 & 931.6 & 647.4 & 194.6 \\
\hline Mn & 2.4 & 7.2 & 4.9 & 10.2 & - & 0.8 & 5.4 & 6.5 & 4.5 & 1.7 & 0.4 & - \\
\hline $\mathrm{Fe}$ & - & 1.5 & 3.5 & 9.5 & - & - & - & - & - & - & - & - \\
\hline Co & - & 0.1 & 0.3 & 0.4 & - & - & 0.5 & 0.4 & 0.4 & 0.1 & 0.2 & \\
\hline $\mathrm{Ni}$ & 0.6 & 0.9 & 0.8 & 1.0 & 0.9 & 1.3 & 1.9 & 1.4 & 1.9 & 1.4 & 1.7 & 1.9 \\
\hline $\mathrm{Zn}$ & - & - & - & 6.1 & - & - & - & - & - & - & - & - \\
\hline \multicolumn{13}{|l|}{ lon components ( $\mu \mathrm{M})$} \\
\hline $\mathrm{F}$ & 0.8 & 1.2 & 0.3 & 0.7 & 1.6 & 1.3 & 0.3 & 0.6 & 1.2 & 1.5 & 0.4 & 2.1 \\
\hline $\mathrm{PO}_{4}{ }^{3-}$ & 5.3 & 2.4 & 7.8 & 21.9 & 129.9 & 2.7 & 3.7 & 1.1 & 0.6 & 1.3 & 0.7 & 7.1 \\
\hline $\mathrm{SO}_{4}{ }^{2-}$ & 7.9 & 16.4 & 35.4 & 73.6 & 109.5 & 20.0 & 11.7 & 43.2 & 19.8 & 76.5 & 20.5 & 25.1 \\
\hline $\mathrm{Cl}$ & 6.9 & 7.1 & 2.6 & 2.2 & 2.3 & 2.2 & 3.8 & 2.4 & 4.4 & 10.3 & 4.3 & 6.2 \\
\hline $\mathrm{NH}_{4}^{+}$ & 2.8 & 20.7 & 0.8 & 2.9 & 34.0 & 88.0 & 224.6 & 2.4 & 0.9 & 2.2 & 457.1 & 328.0 \\
\hline \multicolumn{13}{|l|}{ Amino acids $(\mu \mathrm{M})$} \\
\hline Ala & - & 1.1 & 1.9 & 2.9 & 1.1 & 0.8 & 2.1 & 0.3 & 0.4 & - & 2.2 & 0.4 \\
\hline $\operatorname{Arg}$ & 0.7 & 1.7 & 2.8 & 2.4 & 1.2 & 1.7 & 0.2 & 0.1 & 0.2 & 0.2 & 0.4 & 0.1 \\
\hline Asn & - & 0.7 & 7.5 & 7.6 & 0.5 & 3.9 & 1.0 & - & - & - & 2.3 & 0.9 \\
\hline Asp & 0.9 & 2.0 & 5.4 & 5.5 & 3.4 & 4.5 & 38.2 & 0.1 & 2.6 & 1.4 & 1.6 & 1.4 \\
\hline Cys & - & 0.2 & 0.4 & 0.4 & - & 0.1 & - & - & 0.1 & - & - & - \\
\hline Gln & - & 52.3 & 626.9 & 592.1 & 38.0 & 288.2 & 197.0 & 0.0 & - & - & 111.8 & 53.9 \\
\hline Glu & 1.3 & 4.9 & 14.3 & 13.4 & 7.3 & 8.5 & 156.0 & 0.3 & 67.8 & 1.3 & 3.4 & 3.0 \\
\hline Gly & 0.2 & 0.6 & 0.6 & 0.5 & 0.5 & 0.5 & 0.9 & 0.5 & 0.9 & 0.1 & 0.1 & 0.6 \\
\hline His & - & - & 12.1 & 13.6 & 0.3 & 2.3 & - & - & 0.5 & - & 2.4 & 0.3 \\
\hline lle & - & 8.2 & 53.8 & 66.9 & 2.6 & 9.2 & 5.5 & 0.1 & 1.4 & 0.1 & 7.7 & 1.7 \\
\hline Leu & - & 4.1 & 21.9 & 23.1 & 1.1 & 3.7 & 1.1 & 0.2 & 0.5 & - & 3.5 & 0.6 \\
\hline Lys & - & 1.6 & 1.5 & 1.6 & - & 0.9 & - & - & - & - & 0.5 & 0.1 \\
\hline Met & - & 2.3 & 11.1 & 14.9 & 0.4 & 1.8 & - & - & - & - & 2.7 & 0.2 \\
\hline Phe & - & 8.0 & 29.6 & 38.8 & 0.7 & 3.1 & 0.4 & 0.2 & 1.0 & 0.1 & 1.7 & 0.6 \\
\hline Pro & - & 2.4 & 6.2 & 7.6 & - & - & - & - & - & - & - & - \\
\hline Ser & - & 5.5 & 17.6 & 24.2 & 0.5 & 1.3 & 0.3 & 0.4 & 0.7 & 0.3 & 0.8 & 0.4 \\
\hline Thr & - & 9.9 & 50.3 & 55.5 & 1.9 & 4.9 & 1.5 & 0.2 & 1.8 & 0.1 & 5.3 & 1.1 \\
\hline Trp & - & 0.2 & 0.7 & 0.9 & - & 0.1 & - & - & - & - & - & \\
\hline Tyr & - & 3.0 & 10.1 & 11.8 & 0.8 & 1.6 & 0.3 & - & 0.6 & - & 2.0 & 0.5 \\
\hline Val & - & 12.0 & 74.0 & 88.8 & 3.3 & 15.1 & 10.9 & 0.1 & 1.9 & - & 10.1 & 2.5 \\
\hline Organic acids $(\mu \mathrm{M})$ & & & & & & & & & & & & \\
\hline Citrate & 58.8 & 68.6 & 104.0 & 102.6 & 17.3 & 35.4 & 53.6 & 31.9 & 37.3 & 18.9 & 38.6 & 11.3 \\
\hline Malate & 348.7 & 644.5 & 774.2 & 1186.8 & 261.6 & 491.6 & 1027.4 & 244.2 & 651.9 & 440.3 & 1004.5 & 223.5 \\
\hline Plant hormones (pM) & & & & & & & & & & & & \\
\hline tz & 151.1 & 873.8 & 490.4 & 2213.3 & 310.1 & 101.7 & 27.8 & 74.6 & 528.4 & 902.1 & 208.5 & 72.8 \\
\hline $\mathrm{tZR}$ & 2632.9 & 234.3 & 3875.5 & 11771.0 & 16.6 & 91.8 & 176.8 & 287.7 & 113.6 & 3602.7 & 1.7 & 5.0 \\
\hline tZRPs & 61.4 & 6.2 & 135.5 & 2203.9 & 17.5 & 9.8 & 6.5 & 7.9 & 4.7 & 228.8 & 1.7 & 2.7 \\
\hline$c Z$ & 4.4 & 116.0 & 7.2 & 13.6 & 33.6 & 4.2 & 0.5 & 2.2 & 17.1 & 19.8 & 33.9 & 145.2 \\
\hline$c Z R$ & 19.5 & 76.7 & 32.6 & 71.2 & 7.0 & 4.5 & 0.6 & 3.3 & 8.9 & 32.7 & 3.5 & 81.0 \\
\hline cZRPs & 4.3 & 20.6 & 7.7 & 38.1 & 21.8 & 3.7 & 2.9 & 3.1 & 5.7 & 4.3 & 22.5 & 19.5 \\
\hline $\mathrm{DZ}$ & 15.4 & 62.0 & 23.0 & 52.9 & 3.2 & 2.1 & 1.7 & 7.3 & 44.1 & 68.7 & 2.8 & 1.6 \\
\hline DZR & 184.3 & 18.2 & 154.3 & 290.9 & - & - & 9.3 & 19.0 & 8.7 & 131.5 & - & \\
\hline DZRPs & 8.3 & 2.0 & - & 42.1 & 0.9 & 2.1 & - & 1.4 & 1.5 & 20.2 & 1.3 & 0.9 \\
\hline iP & 10.4 & 400.6 & - & - & 169.5 & 11.8 & 3.9 & 1.6 & 24.7 & 20.2 & 76.7 & 447.4 \\
\hline iPR & 4.5 & 188.8 & 21.7 & 74.5 & 9.6 & 6.3 & - & 0.7 & 8.0 & 30.2 & 5.7 & 93.2 \\
\hline iPRPs & 17.2 & 75.2 & - & - & 65.4 & 0.0 & 13.3 & 9.1 & 19.7 & 10.8 & 61.8 & 47.7 \\
\hline tz7G & 0.7 & 2.1 & - & - & 2.8 & 3.1 & 4.1 & - & 3.9 & - & - & \\
\hline $\mathrm{t} Z 9 \mathrm{G}$ & 1.4 & 1.0 & 23.6 & 56.3 & 1.0 & 3.0 & 3.1 & - & - & - & - & 0.8 \\
\hline cZOG & 68.7 & 43.1 & - & - & 6.0 & - & - & - & 8.4 & 23.6 & 14.2 & 19.8 \\
\hline tZROG & 1.0 & 0.9 & - & - & - & 2.6 & - & 0.4 & - & - & - & \\
\hline cZROG & 8.4 & 4.6 & - & - & 0.8 & 2.5 & 1.6 & 1.2 & 1.6 & 0.0 & 2.7 & 2.9 \\
\hline cZRPsOG & 6.1 & 2.8 & 45.3 & 17.8 & 3.9 & 9.2 & 3.8 & 4.5 & 4.2 & 3.2 & 1.8 & 3.6 \\
\hline iP9G & 1.8 & - & - & - & - & - & - & - & - & - & - & 0.3 \\
\hline IAA & 1.5 & 249.3 & 6.0 & 20.8 & 38.9 & 3.1 & 0.8 & 0.4 & 7.9 & 2.3 & 51.5 & 10.2 \\
\hline IA-lle & - & - & - & - & - & - & - & 2.5 & - & 5.2 & & \\
\hline $\mathrm{GA}_{19}$ & - & - & - & - & - & - & - & - & - & - & 12.8 & 4.8 \\
\hline $\mathrm{GA}_{20}$ & - & - & - & - & - & - & - & - & - & - & - & 1.7 \\
\hline $\mathrm{GA}_{44}$ & 0.8 & 3.8 & 13.1 & 58.1 & 3.7 & 8.4 & - & - & - & 2.7 & 5.8 & 5.7 \\
\hline $\mathrm{GA}_{53}$ & 6.5 & 34.4 & 172.1 & 511.8 & 55.2 & 59.4 & - & - & - & 35.1 & 75.1 & 42.4 \\
\hline ABA & 8871.3 & 1580.3 & 5146.7 & 19220.5 & 4169.6 & 8171.5 & 4731.7 & 3787.4 & 3371.9 & 7864.3 & 3692.4 & 1548.5 \\
\hline Protein $(\mu \mathrm{g} / \mathrm{ml})$ & 11 & 29 & 37 & 20 & 0 & 2 & 8 & 32 & 18 & 34 & 7 & 0 \\
\hline Free sugars $(\mu \mathrm{M})$ & & & & & & & & & & & & \\
\hline Glucose & 72.6 & 314.7 & 33.8 & 15.1 & 1.9 & 1.2 & 2.4 & 137.7 & 49.1 & 45.1 & 1.9 & 2.6 \\
\hline Sucrose & 2.4 & 17.1 & 13.8 & 14.3 & 2.3 & 2.3 & 0.5 & 2.6 & 10.2 & 10.8 & 1.7 & 1.6 \\
\hline
\end{tabular}




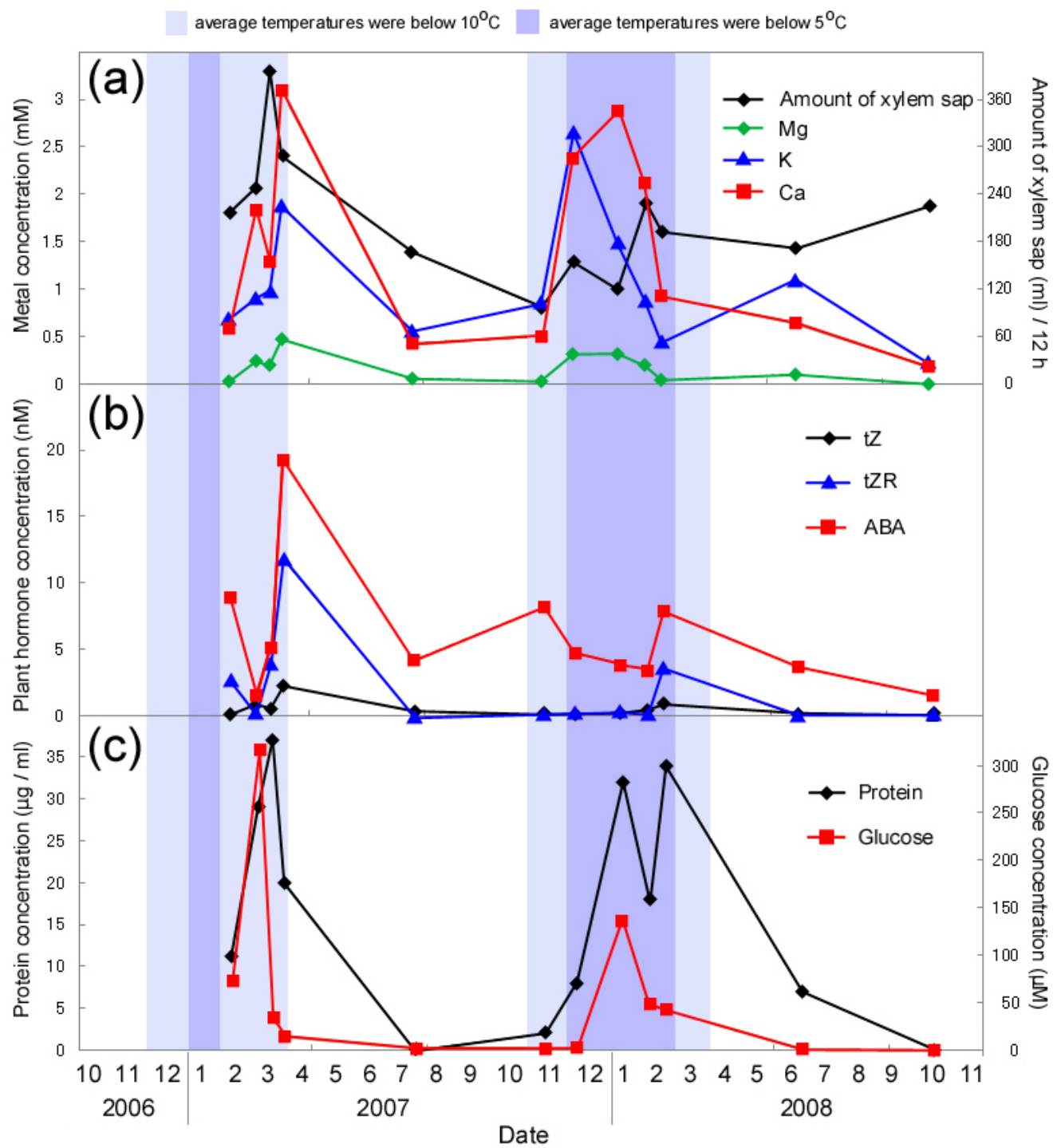

Fig. 3. Seasonal fluctuation in the amount of xylem sap collected for $12 \mathrm{~h}$, and changes in concentrations of inorganic elements (a), plant hormones (b), and free glucose and protein (c) of P. nigra. Light- and dark-shaded areas indicate when average temperatures were below $10^{\circ} \mathrm{C}$ and $5^{\circ} \mathrm{C}$, respectively.

endogenous ABA (Parent et al. 2009). Therefore, the up-regulation of water transport by ABA may cause the increase in xylem sap volume in early spring. The tissues and organs responsible for ABA synthesis remain to be determined.

Peaks of tZR and $\mathrm{tZ}$ in early spring had similar timing to that of the ABA increase in the spring of 2007 and 2008. Cytokinins are involved in the suppression of leaf senescence (Kato et al. 2002, Soejima et al. 1992), lateral bud development (Beveridge et al. 1997), and response to nitrogen availability (Takei et al. 2001). Therefore, the increase in cytokinins in poplar xylem sap may be related to spring shoot growth.

Our results clearly indicated the existence of sea- sonal fluctuations of xylem sap components in Poplar. However, the fluctuation pattern was differed between two investigated seasons. The shift in the peak time and duration of xylem sap components (February to March in 2007; November to February of 2007 and 2008) may be caused by environmental factors. For example, the average temperature was at or below $5^{\circ} \mathrm{C}$ only in January of 2007 but occurred in December of 2007 and in January and February of 2008 (Fig. 1). The longer period of low temperatures in the second season was consistent with an earlier and broader peak in various xylem sap substances. These suggest that low temperatures, possibly below $5^{\circ} \mathrm{C}$, may trigger an increase in xylem sap quantity and a shift in its composition, possibly related to a low tempera- 
ture-induced cold acclimation and break in shoot dormancy (Heide 1993, Espinosa-Ruiz et al. 2004). The ground temperature at a depth of $1 \mathrm{~m}$ (1990 to 1999; provided by the Terrestrial Environmental Research Center, University of Tsukuba; http://www.suiri.tsukuba.ac.jp/TERC/database.html) was about $12^{\circ} \mathrm{C}$ in mid-winter, whereas air temperature was about $5^{\circ} \mathrm{C}$. The ground temperature was much more moderate and constant than air temperature throughout the year at our research site. These temperature data suggest that the low temperature may be perceived in the shoot or surface root. Our results suggest that roots support shoot activity in advance of the induction of shoot growth after dormancy break. To reveal the regulatory environmental factors for root functions more in detail, experiments under artificially controlled conditions will be required, and molecular studies will be also required to elucidate the functions of the xylem sap components.

\section{Acknowledgements}

The authors are grateful to Dr. Louis John Irving (University of Tsukuba, Japan) for his critical reading of the paper. This work was supported in part by the Ministry of Education, Culture, Sports, Science and Technology (MEXT), Grant-in-Aid for Scientific Research (C).

\section{References}

Améglio T, Ewers FW, Cochard H, Martignac M, Vandame M, Bodet C, Cruiziat P 2001 Winter stem pressures in walnut trees: effects of carbohydrates, cooling and freezing. Tree Physiol. 21: 387-394.

Bertrand A, Robitaille G, Castonguay Y, Nadeau P, Boutin R 1997 Changes in ABA and gene expression in cold-acclimated sugar maple. Tree Physiol. 17: 31-37.

Beveridge CA, Symons GM, Murfet IC, Ross JJ, Rameau C 1997 The rms 1 mutant of pea has elevated indole-3-acetic acid levels and reduced zeatin riboside content but increased branching controlled by graft-transmissible signal(s). Plant Physiol. 115: 1251-1258.

Canam T, Mak SWY, Mansfield SD 2008 Spatial and temporal expression profiling of cell-wall invertase genes during early development in hybrid poplar. Tree Physiol. 28: 1059-1067.

Delhaize E, Ryan PR, Randall PJ 1993 Aluminum tolerance in wheat (Triticum aestivum L.) (II. Aluminum-stimulated excretion of malic acid from root apices). Plant Physiol. 103: 695-702.

Escher P, Eiblmeier M, Hetzger I, Rennenberg H 2004 Seasonal and spatial variation of carbohydrates in mistletoes (Viscum album) and the xylem sap of its hosts (Populus x euramericana and Abies alba). Physiol. Plant. 120: 212-219.

Espinosa-Ruiz A, Saxena S, Schmidt J, Mellerowicz E, Miskolczi P, Bakó L, Bhalerao RP 2004 Differential stage-specific regulation of cyclin-dependent kinases during cambial dormancy in hybrid aspen. Plant J. 38: 603-615.
Freundl E, Steudle E, Hartung W 1998 Water uptake by roots of maize and sunflower affects the radial transport of abscisic acid and its concentration in the xylem. Planta 207: 8-19.

Heide OM 1993 Dormancy release in beech buds (Fagus sylvatica) requires both chilling and long days. Physiol. Plant. 89: 187-191.

Hose E, Steudle E, Hartung W 2000 Abscisic acid and hydraulic conductivity of maize roots: a study using celland root-pressure probes. Planta 211: 874-882.

Javot H, Lauvergeat V, Santoni V, Martin-Laurent F, Güçlü J, Vinh J, Heyes J, Franck KI, Schäffner AR, Bouchez D, Maurel C 2003 Role of a single aquaporin isoform in root water uptake. Plant Cell 15: 509-522.

Kato C, Kato H, Asami T, Yoshida S, Noda H, Kamada H, Satoh S 2002 Involvement of xylem sap zeatin-O-glucoside in cucumber shoot greening. Plant Physiol. Biochem. 40: 949-954.

Kohler A, Delaruelle C, Martin D, Encelot N, Martin F 2003 The poplar root transcriptome: analysis of 7000 expressed sequence tags. FEBS Lett. 542: 37-41.

Kojima M, Kamada-Nobusada T, Komatsu H, Takei K, Kuroha T, Mizutani M, Ashikari M, Ueguchi-Tanaka M, Matsuoka M, Suzuki K, Sakakibara H 2009 Highly sensitive and high-throughput analysis of plant hormones using MS-probe modification and liquid chromatography-tandem mass spectrometry: an application for hormone profiling in Oryza sativa. Plant Cell Physiol. 50: 1201-1214.

Lachaud S 1989 Some aspect of phytohormonal participation in the control of cambial activity and xylogenesis in tree stems. Ann. Sci. Forest. 46: 273-276.

Martre P, Morillon R, Barrieu F, North GB, Nobel PS, Chrispeels MJ 2002 Plasma membrane aquaporins play a significant role during recovery from water deficit. Plant Physiol. 130: 2101-2110.

Maurel C 2007 Plant aquaporins: Novel functions and regulation properties. FEBS Lett. 581: 2227-2236.

Mayrhofer S, Heizmann U, Magel E, Eiblmeier M, Müller A, Rennenberg H, Hampp R, Schnitzler JP, Kreuzwieser J 2004 Carbon balance in leaves of young poplar trees. Plant Biol. 6: 730-739.

Parent B, Hachez C, Redondo E, Simonneau T, Chaumont F, Tardieu F 2009 Drought and abscisic acid effects on aquaporin content translate into changes in hydraulic conductivity and leaf growth rate: a trans-scale approach. Plant Physiol. 149: 2000-2012.

Renaut J, Hoffmann L, Hausman JF 2005 Biochemical and physiological mechanisms related to cold acclimation and enhanced freezing tolerance in poplar plantlets. Physiol. Plant. 125: 82-94.

Ruttink T, Arend M, Morreel K, Storme V, Rombauts S, Fromm J, Bhalerao RP, Boerjan W, Rohde A 2007 A molecular timetable for apical bud formation and dormancy induction in poplar. Plant Cell 19: 2370-2390.

Sagi T 1966 Determination of ammonia in sea water by the indophenol method and its application to the coastal and off-shore waters. Oceanogr. Mag. 18: 43-51.

Sakr S, Alves G, Morillon R, Maurel K, Decourteix M, Guilliot A, Fleurat-Lessard P, Julien JL, Chrispeels MJ 2003 Plasma membrane aquaporins are involved in winter embolism recovery in walnut tree. Plant Physiol. 133: 630-641.

Sauter JJ, Iten W, Zimmermann MH 1973 Studies on the release of sugar into the vessels of sugar maple (Acer saccharum). Can. J. Bot. 51: 1-8. 
Soejima H, Sugiyama T, Ishihara K 1992 Changes in cytokinin activities and mass spectrometric analysis of cytokinins in root exudates of rice plant (Oryza sativa L.). Plant Physiol. 100: 1724-1729.

Sterky F, Bhalerao RR, Unneberg P, Segerman B, Nilsson P, Brunner AM, Charbonnel-Campaa L, Lindvall JJ, Tandre K, Strauss SH, Sundberg B, Gustafsson P, Uhlén M, Bhalerao RP, Nilsson O, Sandberg G, Karlsson J, Lundeberg J, Jansson S 2004 A Populus EST resource for plant functional genomics. Proc. Natl. Acad. Sci. USA 101: 13951-13956.

Takei K, Sakakibara H, Taniguchi M, Sugiyama T 2001 Nitrogen dependent accumulation of cytokinins in root and the translocation to leaf: implication of cytokinin species that induces gene expression of maize response regulator. Plant Cell Physiol. 42: 85-93.

Teskey RO, Hinckley TM 1981 Influence of temperature and water potential on root growth of white oak. Physiol. Plant. 52: 363-369.

Tromp J, Ovaa JC 1990 Seasonal changes in the cytokinin composition of xylem sap of apple. J. Plant Physiol. 136: 606-610.

Tuskan GA, Difazio S, Jansson S, Bohlmann J, Grigoriev I, Hellsten U, Putnam N, Ralph S, Rombauts S, Salamov A, Schein J, Sterck L, Aerts A, Bhalerao RR, Bhalerao RP, Blaudez D, Boerjan W, Brun A, Brunner A, Busov V,
Campbell M, Carlson J, Chalot M, Chapman J, Chen GL, Cooper D, Coutinho PM, Couturier J, Covert S, Cronk Q, Cunningham R, Davis J, Degroeve S, Déjardin A, Depamphilis C, Detter J, Dirks B, Dubchak I, Duplessis S, Ehlting J, Ellis B, Gendler K, Goodstein D, Gribskov M, Grimwood J, Groover A, Gunter L, Hamberger B, Heinze B, Helariutta Y, Henrissat B, Holligan D, Holt R, Huang W, Islam-Faridi N, Jones S, Jones-Rhoades M, Jorgensen R, Joshi C, Kangasjärvi J, Karlsson J, Kelleher C, Kirkpatrick R, Kirst M, Kohler A, Kalluri U, Larimer F, Leebens-Mack J, Leplé JC, Locascio P, Lou Y, Lucas S, Martin F, Montanini B, Napoli C, Nelson DR, Nelson C, Nieminen K, Nilsson O, Pereda V, Peter G, Philippe R, Pilate G, Poliakov A, Razumovskaya J, Richardson P, Rinaldi C, Ritland K, Rouzé P, Ryaboy D, Schmutz J, Schrader J, Segerman B, Shin H, Siddiqui A, Sterky F, Terry A, Tsai CJ, Uberbacher E, Unneberg P, Vahala J, Wall K, Wessler S, Yang G, Yin T, Douglas C, Marra M, Sandberg G, Van de Peer Y, Rokhsar D 2006 The genome of black cottonwood, Populus trichocarpa (Torr. \& Gray). Science 313: 1596-1604.

Yamazaki T, Kawamura Y, Minami A, Uemura M 2008 Calcium-dependent freezing tolerance in Arabidopsis involves membrane resealing via synaptotagmin SYT1. Plant Cell 20: 3389-3404. 